\title{
Effect of Number of Touches and Exercise Duration on the Kinematic Profile and Heart Rate Response During Small-Sided Games in Soccer
}

\author{
by \\ David Casamichana1, Luis Suarez-Arrones², Julen Castellano², \\ Jaime San Román-Quintana ${ }^{3}$
}

\begin{abstract}
This study aimed to examine the effect of exercise duration and the number of touches allowed during possession on time-motion characteristics and the physiological responses of soccer players in 6 vs. 6 small-sided games (SSGs) lasting 12 minutes. The analysis divided each game into two 6-min periods and we compared two formats: free play (SSGFP) vs. a maximum of two touches per individual possession (SSG 2 ). Participants were 12 semi-professional players (age: $22.7 \pm 4.3$ years; body height: $177.5 \pm 4.9 \mathrm{~cm}$; body mass: $74.9 \pm 6.3 \mathrm{~kg}$ ) and the following variables were measured by means of heart rate monitors and GPS devices: mean heart rate (HRmean), time spent in each exercise intensity zone, total distance covered, total distance covered in different speed zones, number of accelerations at different intensities, maximum speed reached, player load, and the work-to-rest ratio. The results showed that in SSGFP there was a decrease in the intensity of physical parameters during the second 6-min period (6-12 min), whereas this decrease was not observed when a maximum of two touches per individual possession was allowed. During the second period (6-12 min) of SSG2T there was an increase in HRmean and in the time spent in high exercise intensity zones, but these differences were not observed in SSGFP. The value of these findings for soccer coaches is that they illustrate how different technical, tactical or conditioning objectives could be addressed by altering the length and format of the SSG used in training.
\end{abstract}

Key words: soccer, bout duration, exercise intensity, small sided games, time-motion, GPS device, heart rate.

\section{Introduction}

Small-sided games (SSGs) are widely used as part of training (Aguiar et al., 2012) in several sports such as soccer (Hill-Haas, Dawson et al., 2011; Köklü et al., 2012) or rugby (Gabbett et al., 2012; Kennett et al., 2012) and they enable coaches to address various objectives simultaneously, for example, technical skills (Jones and Drust, 2007), conditioning (Hill-Haas, Dawson et al., 2009), tactical behavior (Almeida et al., 2013; Sampaio and Maçãs, 2012), or psychological aspects (Flanagan and Merrick, 2002). If training is to be implemented systematically, the different elements involved need to be taken into consideration when designing drills, as these elements can affect the demands placed on players (Fanchini et al., 2011; Tessitore et al., 2006). One key element is the duration of a training drill, as this influences both the amount and intensity of training demands (Fanchini et al., 2011). Research to date has

\footnotetext{
1 - Faculty of Physiotherapy and Speech Therapy Gimbernat-Cantabria. University School associated with the University of Cantabria (EU Gimbernat-Cantabria). Torrelavega, Spain.

2 - MasterdeFutbol. Pablo de Olavide University. Seville. Spain.

${ }^{3}$ - Faculty of Physical Activity and Sport Sciences. University of the Basque Country (UPVIEHU). Vitoria-Gasteiz, Spain.
} 
considered a wide range of bout durations when studying the effect of training drills, from as little as 1.5 minutes (Aroso et al., 2004; Dellal et al., 2008) up to 24 minutes (Hill-Haas, Coutts et al., 2010).

A further aspect to be considered is the duration and number of repetitions. Increasing the duration could influence player's behavior by encouraging greater self-regulation and reducing exercise intensity. Intensity may also decrease as a result of fatigue (Fanchini et al., 2011). As for the number of repetitions, several different proposals have been reported in the context of SSGs, ranging from 25 (Rodrigues et al., 2007) down to 10 (Katis and Kellis, 2010) or even a single bout (Hill-Haas, Coutts et al., 2010). However, the most common format involves between three and six repetitions (Hill-Haas et al., 2011).

It is difficult to compare the effects of the temporal dimension across studies that differ not only in the duration of bouts but also in the number of repetitions and other related variables (number of players per side, pitch size, use of goals, among others), not least as these aspects sometimes vary within the same study (Koklü et al., 2011). In fact, very few studies have specifically examined the effect of the temporal variable on player's response. Tessitore et al. (2006) studied exercise intensity in 6 vs. 6 drills of different durations ( 3 and $8 \mathrm{~min}$ ) and found that during 8-min drills, players spent more time above the anaerobic threshold. More recently, Fanchini et al. (2011) sought to determine whether an increase in the duration of repetitions $(2,4$, and $6 \mathrm{~min}$ ) affected exercise intensity and technical performance during $3 v s$. 3 SSGs. They found that the heart rate was significantly lower during the 6-min bout compared with the 4-min bout ( $87.8 \pm$ $2.8 \% \mathrm{HR}_{\max }$ vs. $\left.88.5 \pm 3.1 \% \mathrm{HR}_{\max }\right)$, although there were no significant differences in terms of technical performance. The authors concluded that an increase in duration could lead to a decrease in intensity, although the difference was unlikely to be of sufficient magnitude to induce different training adaptations.

Despite the relevance of this research, those studies which have considered the temporal dimension of training have not specifically examined its effect on the physical response of players. Consequently, occurrence of the acute effects of exercise duration in player's performance is not clear. In light of this, the aims of the present study were as follows: 1) to analyze the physical and physiological response of players across 12-min SSGs that were divided into two 6min periods; and 2) to examine this temporal influence in two different SSGs: free play (SSGFP) versus a maximum of two touches per individual possession (SSG2T).

\section{Material and Methods}

\section{Sample}

Participants were 12 semi-professional male soccer players (age: $22.7 \pm 4.3$ years; body height: $177.5 \pm 4.9 \mathrm{~cm}$; body mass: $74.9 \pm 6.3 \mathrm{~kg}$; YYIRT1: $2360 \pm 638.4 \mathrm{~m}$ ) who played for the same team (senior division). They had played federation soccer for a mean of 12.5 years prior to the study. Their standard training involved three or four sessions per week (each lasting around 90 min) in addition to a competitive match. All the players were notified of the research design and its requirements, as well as the potential benefits and risks, and they gave their informed consent prior to the start. The Ethics Committee of the University of the Basque Country (CEISH) gave its institutional approval of the study.

\section{Procedure}

The study was conducted over a threeweek period (January, under similar weather conditions) of the 2010-11 competitive season. Players were familiarized previously with the two types of SSG and the devices that would be used during the study. One week before the experimental part of the study commenced, players simultaneously performed the Yo-Yo Intermittent Recovery Test-Level 1 (YYIRT1) in order to determine their HRmax. This was done on an outdoor artificial pitch with the players wearing soccer cleats.

Four training sessions (with an interval of at least $48 \mathrm{~h}$ between them) were subsequently conducted on an outdoor artificial grass pitch and at similar times of the day (8:30 p.m.) in order to avoid circadian effects on performance (Drust et al., 2005). Each session began with a 15-min standard warm-up followed by a single drill lasting $12 \mathrm{~min}$. This drill was a SSG involving the same number of players per side ( 6 vs. 6 without goalkeepers) and played in two different ways: sessions 1 and 3 involved free play whereas in sessions 2 and 4 each player was allowed a 
maximum of two touches per possession.

In order to avoid potential imbalances between the two teams and to ensure their equivalence, we followed the procedure proposed by Casamichana and Castellano (2010), whereby players were classified according to the following variables: minutes of competitive play, performance on the YYIRT1, usual playing position and subjective appraisal of the coach.

To avoid the pacing effect (Sampaio et al., 2013), coaches were present during all the SSGs in order to offer encouragement to the players (Rampinini et al., 2007). In addition, eight footballs were distributed around the edge of the pitch in order to maximize the effective playing time (Casamichana and Castellano, 2010). All participants were advised to maintain their normal diet with special emphasis being placed on a high intake of water and carbohydrates.

\section{Independent Variables}

The independent variables were the two 6-min periods (0.0-5.9 $\mathrm{min}$ and 6.0-12.0 $\mathrm{min}$ ) within each 6 vs. 6 SSG. The aim of the players during these 12-min SSGs was simply to maintain possession for as long as possible. Two types of game with possession rules were used: free play vs. a maximum of two touches per individual possession. The pitch size was the same in all the SSGs $(60 \times 49 \mathrm{~m})$, such that the relative area per player was $245 \mathrm{~m}^{2}$. Except for the offside rule, the standard rules of 11-a-side soccer were followed.

\section{Physiological Profile: Heart Rate}

The physiological profile was assessed on the basis of the heart rate (Esposito et al., 2004), which was recorded every $5 \mathrm{~s}$ using a telemetric device (Polar Team Sport System, Polar Electro Oy, Finland). Exercise intensity was expressed in relation to the individual maximal heart rate (HRmax) obtained during the YYIRT1 (Bangsbo et al., 2008). HR data were classified based on the percentage of total time spent in each of the following four $\mathrm{HR}$ zones: $<80 \% \mathrm{HR}_{\max }, \quad 81$ $90 \% \mathrm{HR}_{\max }, 91-100 \% \mathrm{HR}_{\max }$, and $>80 \% \mathrm{HR}_{\max }$ (the latter accumulates all values above $80 \%$ of $\mathrm{HR}_{\max }$ ). Data were categorized into HR zones using the software Logan Plus 4.5.0 (Catapult Innovations, 2010).

\section{Time-Motion Characteristics: Distance Covered and Number of Accelerations Performed}

The running profile was measured using a portable global positioning system (GPS) device operating at a sampling frequency of $10 \mathrm{~Hz}$ (MinimaxX 4.0, Catapult Innovations). After recording, the data were downloaded to a PC and analyzed using Logan Plus 4.5.0 (Catapult Innovations, 2010). Similarly to previous studies, four speed zones (0.1-6.9, 7.0-12.9, 13.0-17.9, and $\geq 18.0 \mathrm{~km} \cdot \mathrm{h}^{-1}$ ) (Hill-Haas, Dawson et al., 2009; Impellizzeri et al., 2006) and four acceleration zones $\left(1.0-1.4,1.5-1.9,2.0-2.4\right.$, and $\left.\geq 2.5 \mathrm{mss}^{-2}\right)$ (Varley et al., 2012) were established. The total distance covered (TD), maximum speed reached $\left(\mathrm{V}_{\max }\right)$, work-to-rest ratio, player load, distance covered within designated speed zones and the number of accelerations within designated zones were all calculated. Player Load (PL) is a measure calculated using the data obtained via the triaxial accelerometer incorporated within the GPS device (Boyd et al., 2011; Casamichana et al., 2013; Gastin et al., 2013). PL has demonstrated high reliability, both within and between devices, thereby suggesting that accelerometers are a viable tool for tracking activity changes during exercise (Akenhead et al., 2013; Varley et al., 2012). PL was calculated using the following formula and expressed per minute of practice $\left(\mathrm{AU} \bullet \mathrm{min}^{-1}\right)$ :

Player load $=\sqrt{ }((($ acat $=i+1-$ acat $=1) 2+$ $\left.\left.\left(\operatorname{act}_{t}=\mathrm{i}+1-\operatorname{act}_{\mathrm{t}}=1\right) 2+\left(\mathrm{acv} t=\mathrm{i}+1-\mathrm{acvt}_{\mathrm{t}}=1\right) 2\right) / 100\right)$

where aca is the acceleration in the anteroposterior or horizontal axis, act is the acceleration in the transverse or lateral axis, acv is the acceleration in the vertical axis, $i$ is the current time, and $t$ is time.

The technology used to collect these data has been previously validated and shown to be reliable for monitoring high intensity activities in soccer players (Castellano et al., 2011; Varley et al., 2012).

\section{Statistical analysis}

Variables are presented as mean $( \pm S D)$. The precision of estimates is indicated with $90 \%$ confidence limits. In addition to the analyses (i.e., paired $t$ tests) conducted to identify any statistically significant differences in movement patterns and heart rate responses during both types of SSG, pairwise comparisons were analyzed for practical significance using magnitude-based inferences (Hopkins, 2006). The movement patterns and heart rate data were logtransformed prior to analysis in order to reduce non-uniformity of error. Intraclass correlation 
coefficient (ICC) with 95\% CI was used to determine between-subject reliability of the SSG. Within-subject variation for the SSG was determined by calculating the coefficient of variation $(\mathrm{CV})$. Standardized differences or effect sizes (ES, 90\% confidence interval) in SSG physical responses and probabilities were calculated to establish whether the true (unknown) differences were lower than, similar to, or higher than the smallest worthwhile difference $(0.2$ multiplied by the between-subject standard deviation, based on the Cohen's effect size criterion). Quantitative chances of higher or lower differences were evaluated qualitatively as follows (Batterham and Hopkins, 2006; Hopkins et al., 2009): $<1 \%$ is almost certainly not, $<5 \%$ is very unlikely, $<25 \%$ is unlikely/probably not, 25 $75 \%$ is possibly/possibly not, $>75 \%$ is likely/probably, $>95 \%$ is very likely, and $>99 \%$ is almost certainly. A substantial effect was set at $>75 \%$. If the chance of higher or lower differences was $>75 \%$, the true difference was assessed as clear (substantial).

\section{Results}

\section{Kinematic profile}

Running data for both types of SSG are presented in Table 1 and Figure 1. Test-retest reliability for total distance covered, PL, heart rate, maximum speed and work-to-rest ratio as measured by the CV were $7 \%(1-32 \%), 7 \%(0-$ $24 \%), 2 \%(0-11 \%), 10 \% 05-31 \%)$ and $18 \%(1-58 \%)$, respectively, and the ICC ( $95 \% \mathrm{CI})$ ranged from 0.79 to 0.95 . Players' movement patterns were relatively stable during SSG $_{2 \mathrm{~T}}$ while maximum speed was higher $(+6.2 \%$, Table 1$)$ in the second 6 min period of these games.

During the SSGFr a substantial decrease was observed in the second 6-min period in total distance covered $(-10.4 \%$, Table 1$)$, distance covered at speeds of $7.0-12.9 \mathrm{~km} \cdot \mathrm{h}^{-1}(-20.2 \%$, Figure 1), 13.0-17.9 $\mathrm{km} \cdot \mathrm{h}^{-1}(-22.7 \%$, Figure 1), $\geq 18$ $\mathrm{km} \cdot \mathrm{h}^{-1}(-32.2 \%$, Figure 1), work:rest ratio $(-27.8 \%$, Table 1$)$ and player load (-16.4\%, Table 1$)$.

\section{Heart Rate Responses}

During $\mathrm{SSG}_{2 \mathrm{~T}}$ the mean heart rate (expressed as a percentage of the HRmax) increased substantially during the second 6-min period, reaching $89.3 \pm 3.1 \% \mathrm{HR} \max$ as compared with 83.8 $\pm 4.3 \% \mathrm{HR}_{\max }$ in the first 6 -min period $(+6.2 \%$, Almost Certainly). This difference was not reflected between the first and second 6-min periods during SSGFp $\left(89.0 \pm 3.1 \% \mathrm{HR}_{\max }\right.$ vs. $90.4 \pm 2.5 \%$ $H_{\text {max, }}$ respectively). Figure 2 shows players' HR responses and the percentage of playing time spent in each HR zone expressed as a percentage of the HRmax. During the second 6-min period in both types of SSG, players showed a substantial increase in the percentage of time spent at $>80 \%$ $\mathrm{HR}_{\max }(+22.2 \%$ and $+4.1 \%$, respectively; Figure 2$)$, although the percentage of time spent at $91-100 \%$ $\mathrm{HR}_{\max }$ only increased substantially in $\mathrm{SSG}_{2 \mathrm{~T}}(+49 \%$; Figure 2).

\section{Discussion}

This study examined the physiological and physical responses in soccer players across 6 vs. 6 SSGs lasting a total of 12 minutes. The aim was to analyze the physical and physiological response across 12-min SSGs and examine the influence of playing time with two different rules: free play versus a maximum of two touches per individual possession. The main findings of the present study were as follows: 1) there was a substantial decrease in running performance during the second 6-min period in SSGFP; 2) the mean heart rate and the amount of time players spent in high exercise intensity zone ( $\left.>90 \% \mathrm{HR}_{\max }\right)$ increased during the second 6-min period during SSG 2 T but not in SSGFr.

Total distance covered during SSGFP decreased substantially during the second 6-min period (6-12 $\mathrm{min})$, due specifically to less distance being covered at speeds $\geq 7.0 \mathrm{~km} \cdot \mathrm{h}^{-1}$. These results were similar to those reported by Dellal, LagoPeñas et al. (2011), although these authors concluded that the observed decrease was likely due to the accumulated number of repetitions, since the duration of each bout was held constant. This decrease in movement patterns was also noted by Casamichana et al. (2013) when comparing SSGs with a total duration of 16 minutes and played in either a continuous or intermittent format. When an intermittent format was used, the total distance covered by players was greater than in case of the continuous game, where a decrease in intensity was observed after the first 4 minutes of play. These results are also consistent with the findings of Hill-Haas et al. (2009) who observed that greater distances were covered at high and sprint speed when the format used was intermittent $(4$ repetitions $\times 6$ min 
duration) rather than continuous (24 $\mathrm{min}$ duration). The continuous format used in the present study likewise produced a decrease in the intensity of movement variables during the second 6-min period (6-12 $\mathrm{min}$ ) of the drill, an aspect that needs to be taken into consideration when designing a training schedule.

\begin{tabular}{|c|c|c|c|c|}
\hline \multicolumn{5}{|c|}{$\begin{array}{l}\text { Running profile and player load for each 6-min period in the } \\
\text { two types of small-sided game. Data are mean } \pm S D\end{array}$} \\
\hline Variables & $\begin{array}{c}0.0-5.9 \\
\min \end{array}$ & $6.0-12.0 \mathrm{~min}$ & $\mathrm{ES} \pm 90 \% \mathrm{CL}$ & $\begin{array}{l}\text { Qualitative } \\
\text { Assessment }\end{array}$ \\
\hline & \multicolumn{4}{|c|}{ SSGFP } \\
\hline Total distance covered (m) & $716.3 \pm 77.3$ & $642.2 \pm 91.1$ & $0.94 \pm 0.35$ & Almost Certainly \\
\hline Maximum speed $\left(\mathrm{km} \cdot \mathrm{h}^{-1}\right)$ & $18.8 \pm 2.2$ & $17.4 \pm 2.6$ & $0.63 \pm 0.74$ & Likely \\
\hline Accelerations of $1.0-1.4 \mathrm{~m} \cdot \mathrm{s}^{-2}$ & $4.4 \pm 2.2$ & $4.8 \pm 4.0$ & $0.08 \pm 0.75$ & Unclear \\
\hline Accelerations of $1.5-1.9{\mathrm{~m} \cdot \mathrm{s}^{-2}}^{-2}$ & $2.1 \pm 1.5$ & $0.8 \pm 1.0$ & $0.12 \pm 1.84$ & Unclear \\
\hline Accelerations of $2.0-2.4{\mathrm{~m} \cdot \mathrm{s}^{-2}}^{-2}$ & $0.2 \pm 0.4$ & $0.6 \pm 0.7$ & $0.87 \pm 1.06$ & Likely \\
\hline Accelerations $\geq 2.5 \mathrm{~m} \cdot \mathrm{s}^{-2}$ & $1.5 \pm 1.4$ & $1.9 \pm 1.7$ & $0.02 \pm 1.27$ & Unclear \\
\hline Work:rest ratio & $3.6 \pm 1.2$ & $2.6 \pm 0.9$ & $0.89 \pm 0.35$ & Almost Certainly \\
\hline \multirow[t]{2}{*}{ Player load } & $91.9 \pm 12.9$ & $76.8 \pm 13.1$ & $1.20 \pm 0.70$ & Very Likely \\
\hline & \multicolumn{4}{|c|}{$\mathrm{SSG}_{2 \mathrm{~T}}$} \\
\hline Total distance covered (m) & $680.7 \pm 68.7$ & $683.0 \pm 51.2$ & $0.05 \pm 0.53$ & Unclear \\
\hline Maximum speed $\left(\mathrm{km} \cdot \mathrm{h}^{-1}\right)$ & $18.2 \pm 1.5$ & $19.4 \pm 3.0$ & $0.63 \pm 0.79$ & Likely \\
\hline Accelerations of $1.0-1.4 \mathrm{~m} \cdot \mathrm{s}^{-2}$ & $4.3 \pm 2.8$ & $4.7 \pm 3.0$ & $0.07 \pm 0.69$ & Unclear \\
\hline Accelerations of $1.5-1.9{\mathrm{~m} \cdot \mathrm{s}^{-2}}^{-2}$ & $1.3 \pm 1.3$ & $0.8 \pm 1.3$ & $0.12 \pm 4.6$ & Unclear \\
\hline Accelerations of $2.0-2.4 \mathrm{~m} \cdot \mathrm{s}^{-2}$ & $0.6 \pm 0.7$ & $0.7 \pm 0.5$ & $0.60 \pm 1.74$ & Unclear \\
\hline Accelerations $\geq 2.5 \mathrm{~m} \cdot \mathrm{s}^{-2}$ & $1.3 \pm 1.4$ & $1.4 \pm 1.2$ & $0.00 \pm 1.46$ & Unclear \\
\hline Work:rest ratio & $3.1 \pm 1.1$ & $2.9 \pm 0.7$ & $0.00 \pm 0.49$ & Unlikely \\
\hline Player load & $83.6 \pm 13.2$ & $82.6 \pm 11.5$ & $0.06 \pm 0.45$ & Unclear \\
\hline
\end{tabular}

ES: effect size; CL: confidence limits. 

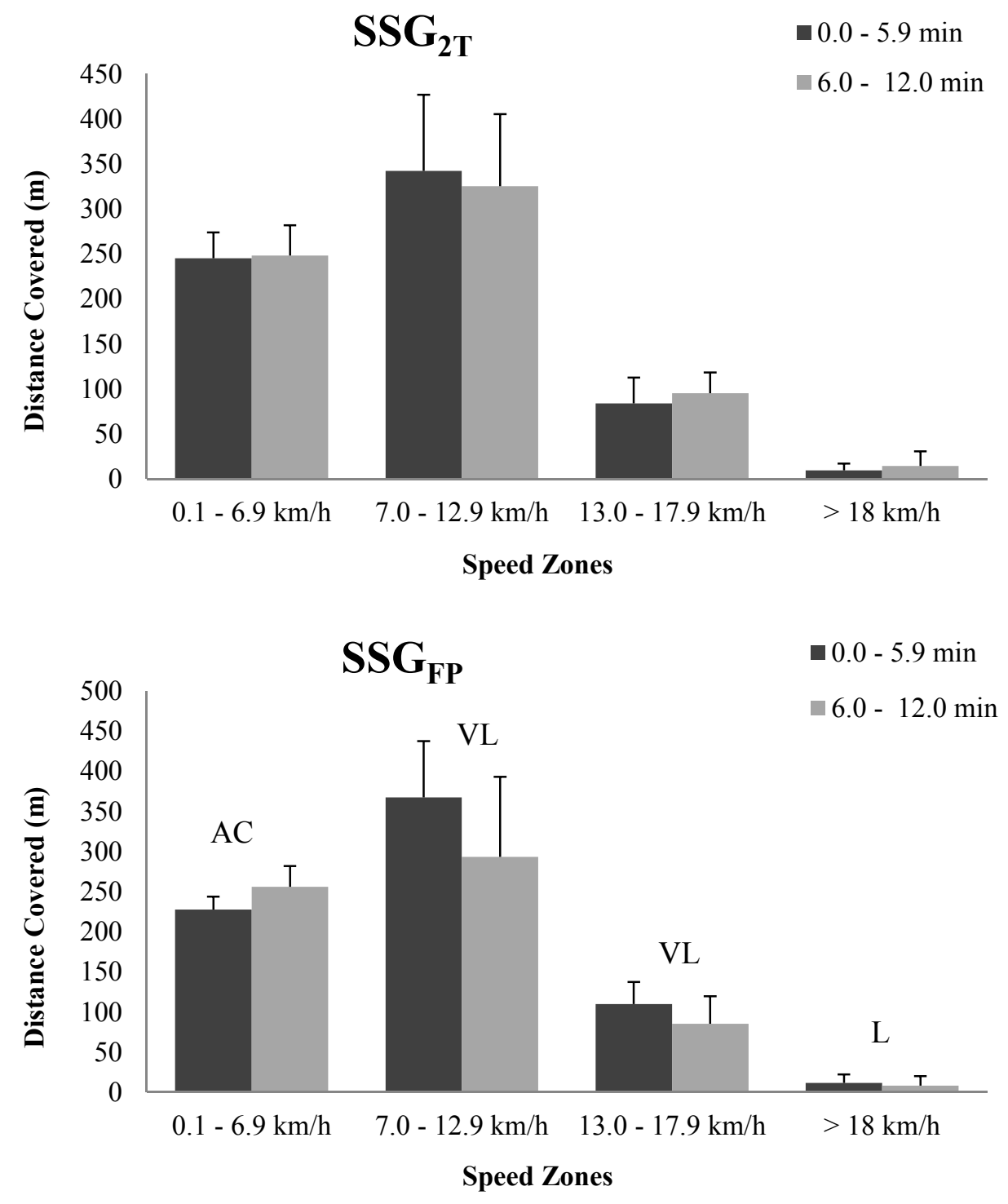

Figure 1

Distance $(m)$ covered within designated speed zones during each 6-min period. SSGFP: small-sided game with free play; SSG2T: small-sided game with a maximum of two touches per individual possession. L: Likely; VL: Very Likely; AC: Almost Certainly. Data are mean $\pm S D$ 

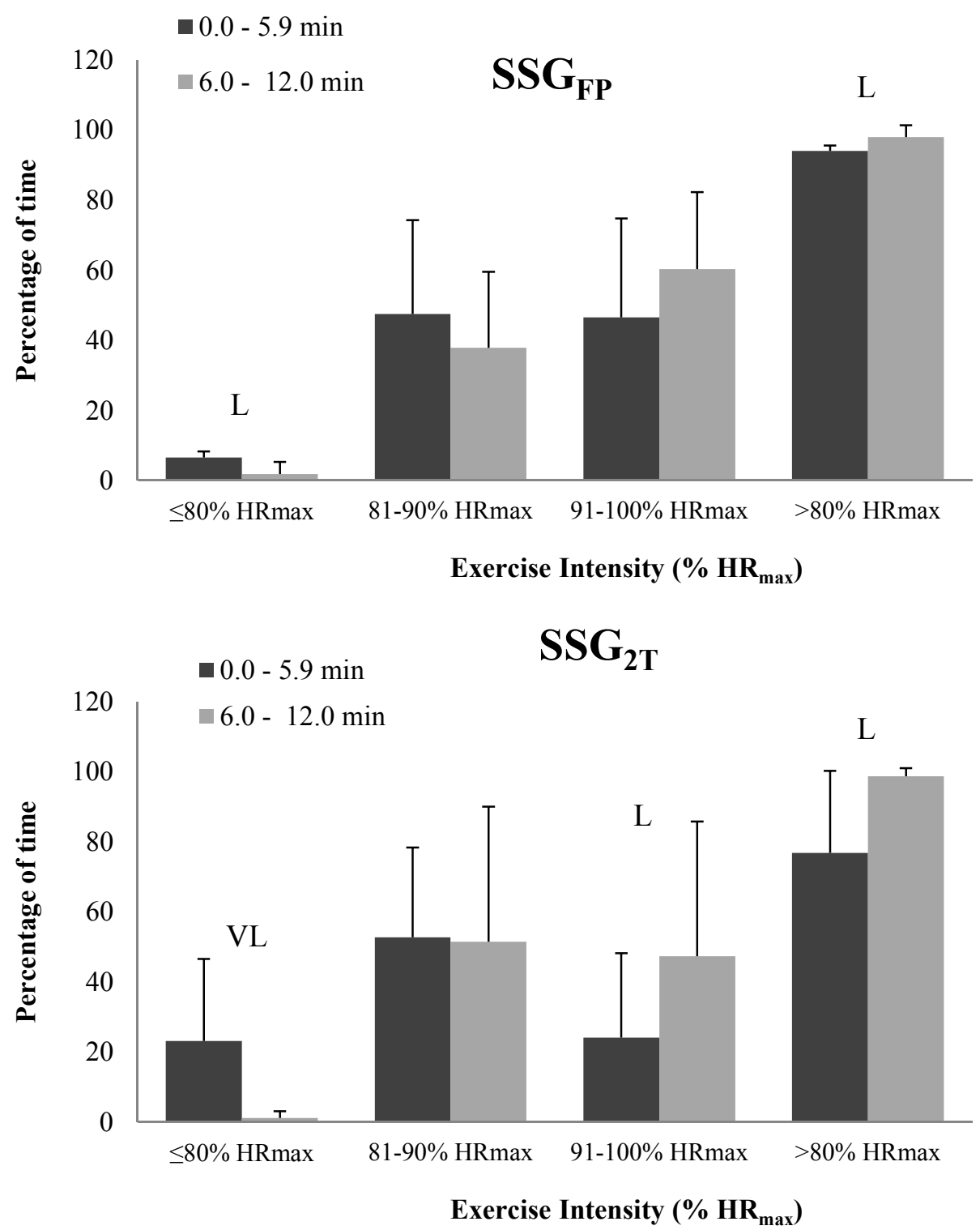

Figure 2

Percentage of playing time spent in each exercise intensity zone during each 6-min period. SSGFP: small-sided game with free play; SSG 2 : small-sided game with a maximum of two touches per individual possession. L: Likely; VL: Very Likely. Data are mean $\pm S D$ 
This is the first study with soccer players that has described the differences between accelerations and decelerations during SSG. Previously, in Australian football (Aughey, 2012) a substantial reduction in the amount of number of maximal accelerations when the competition progressed was observed. Our results during SSGFr also indicated a substantial reduction in PL, the work-to-rest ratio and maximum speed during the second 6-min period (6-12 $\mathrm{min})$, whereas the number of accelerations in the range $2.0-2.4 \mathrm{~m} \cdot \mathrm{s}^{-2}$ increased slightly during the same period. With regard to exercise intensity, the mean heart rate did not differ between the two 6-min periods, although players did spend substantially longer time at $>80 \% \mathrm{HR}_{\max }$ during the second period (6-12 $\mathrm{min}$ ) what perhaps could be caused by fatigue.

Running performance during $\mathrm{SSG}_{2 \mathrm{~T}}$ revealed no differences in movement patterns between the two 6-min periods with the exception of the maximum speed reached, which increased substantially during the second period. Interestingly, the mean heart rate increased during the second 6-min period in the $\mathrm{SSG}_{2 \mathrm{~T}}$, there being a substantial reduction in the amount of time players spent at $<80 \% \mathrm{HR}_{\max }$. These results were consistent with previous studies that have reported an increase in mean intensity as exercise duration gets longer (Tessitore et al., 2006), being this effect more marked in continuous as opposed to intermittent formats (Hill-Haas, Rowsell et al., 2009). Although it is an aspect that was not considered in the present study, the observed difference may be partly due to the time needed for the heart rate to rise following the start of exercise, which would account for the fact that players spent more time at $<80 \% \mathrm{HR}_{\max }$ during the first period. Specifically, it is necessary to take into account the first minute of exercise, this being the time required for players to achieve a high heart rate (Fanchini et al., 2011). A further point to note is that the technical and tactical difficulties produced during the two-touch rule could increase the time which players need in order to adapt to the dynamics of play; indeed, the likelihood of a greater number of ball exchanges could mean that players need longer to achieve a high heart rate. This hypothesis is supported by the fact that players spent a longer time at $<80 \% \mathrm{HR}_{\max }$ during the first period in $\mathrm{SSG}_{2 \mathrm{~T}}$ than they did during the corresponding period of the
SSGFP.

The number of touches that individual players are allowed to make in possession of the ball, is a variable that is commonly manipulated by coaches, and it may affect the physical and physiological response of players during SSGs (Aroso et al., 2004; Dellal, Chamari et al., 2011; Dellal, Hill-Haas et al., 2011; Dellal, Lago-Peñas et al., 2011; Sampaio et al., 2007). Previous studies (Dellal et al., 2011; Dellal, Owen et al., 2012) showed that playing with a less number of touches allowed for increased intensity of various parameters (perceived exertion, blood lactate concentration, total distance covered, and distance covered at high intensity). However, in the present study and despite it not being one of the objectives sought, the values of physical load were higher when there was no limit of touches. A possible explanation for this finding, which is contrary to the published data, is that a limit on the number of individual touches may affect players differently depending on their competitive level (Dellal, Hill-Haas et al., 2011), such that those with greater technical and tactical skills, and those who are used to playing with two or fewer touches (Dellal et al., 2010), are better able to adapt to such a limitation. More research is required regarding the extent to which the modification of variables in SSGs may have different effects depending on the motor skill level of the players involved.

The results of the present study showed that the duration of exercise can affect players' responses, and this highlights the need for the length of drills to be intentionally controlled. If the aim of training is to produce greater cardiovascular output, longer drills should be prescribed. Conversely, if the objective is to encourage high-intensity activity, shorter drills would be more appropriate. Coaches should also take into account that if they decide to limit the number of touches allowed per individual possession, players will take longer to reach $80 \%$ of their HRmax than would be the case in SSGFr.

Changes in any rule during SSGs should be introduced thoughtfully because the effect on physiological and physical responses appears to be influenced by the motor competence of the players involved, by the skill and fluidity with which they are able to perform the drill. 


\section{Acknowledgements}

We gratefully acknowledge the support of the Spanish government project Observación de la interacción en deporte y actividad física: Avances técnicos y metodológicos en registros automatizados cualitativos-cuantitativos (Secretaría de Estado de Investigación, Desarrollo e Innovación del Ministerio de Economía y Competitividad) during the period 2012-2015 [Grant DEP2012-32124].

\section{References}

Aguiar M, Botelho G, Lago C, Maças V, Sampaio J. A review on the effects of soccer small-sided games. J Hum Kinet, 2012; 33: 103-113

Akenhead R, Hayes P, Thompson K, French D. Diminutions of acceleration and deceleration output during professional football match play. J Sci Med Sport, 2013; 6: 556-561

Almeida CA, Ferreira AP, Volossovitch A. Offensive sequences in youth soccer: effects of experience and small-sided games. J Hum Kinet, 2013; 36: 97-106

Aroso J, Rebelo N, Gomes-Pereira, J. Physiological impact of selected game-related exercises. J Sport Sci, 2004; 22: 522

Bangsbo J, Iaia FM, Krustrup P. The Yo-Yo Intermittent Recovery Test: A Useful Tool for Evaluation of Physical Performance in Intermittent Sports. Sports Med, 2008; 38: 37-51.

Batterham AM, Hopkins WG. Making meaningful inferences about magnitudes. Int J Sports Physiol Perform, 2006; $1: 50-57$

Boyd LJ, Ball K, Aughey RJ. The reliability of MinimaxX accelerometers for measuring physical activity in Australian football. Int J Sports Physiol Perform, 2011; 6: 311-321

Casamichana D, Castellano J. Time-motion, heart rate, perceptual and motor behaviour demands in smallsides soccer games: Effects of pitch size. J Sport Sci, 2010; 28: 1615-1623

Casamichana D, Castellano J, Calleja-González J, San Román J, Castagna J. Relationship between indicators of training load in soccer players. J Strength Cond Res, 2013; 27: 369-374

Casamichana D, Castellano J, Dellal A. Influence of different training regimes on physical and physiological demands during small-sided soccer games: continuous vs. intermittent format. J Strength Cond Res, 2013; 27: 690-697

Castellano J, Casamichana D, Calleja-González J, San Román J, Ostojic SM. Reliability and accuracy of $10 \mathrm{~Hz}$ GPS devices for short-distance exercise. J Sports Sci Med, 2011; 10: 233-234

Dellal A, Lago-Peñas C, Chamari K. Effect of the number of ball touch within of 4 vs. 4 small-sided soccer games. Int J Sports Physiol Perform, 2011; 6: 322-33

Dellal A, Chamari K, Pintus A, Girard O, Cotte T, Keller D. Heart rate responses during small-sided games and short intermittent running training in elite soccer players: a comparative study. J Strength Cond Res, 2008; 22: 1449-1457

Dellal A, Hill-Haas S, Lago-Peñas, C, Chamari, K. Small-sided games in soccer: amateur vs. professional players' physiological responses, physical, and technical activities. J Strength Cond Res, 2011; 25: 23712381

Dellal A, Owen A, Wonge DP, Krustrup P, Van Exsel M, Mallo J. Technical and physical demands of small vs. large sided games in relation to playing position in elite soccer. Hum Mov Sci, 2012; 31: 957-969

Dellal A, Wong DP, Moalla W, Chamari K. Physical and technical activity of soccer players in the French First League - with special reference to their playing position. Int Sport Med J, 2010; 11: 278-290

Drust B, Waterhouse J, Atkinson G, Edwards B, Reilly T. Circadian rhythms in sports performance: an update. Chronobiol Int, 2005; 22: 21-44

Espósito F, Impellizzeri FM, Margonato V, Vanni R, Pizzini G, Veicsteinas A. Validity of heart rate as an indicator of aerobic demand during soccer activities in amateur soccer players. Eur J Appl Physiol, 2004; 93: 167-172 
Fanchini M, Azzalin A, Castagna C, Schena F, McCall A, Impellizzeri FM. Effect of bout duration on exercise intensity and technical performance of small-sided games in soccer. J Strength Cond Res, 2011; 25: 453458

Flanagan T, Merrick E. Quantifying the workload of soccer players. In W. Spinks, T. Reilly, \& A. Murphy (Eds.), Science and Football IV. London: Routledge, 341-349; 2002

Gabbett TJ, Abernethy B, Jenkins DG. Influence of field size on the physiological and skill demands of smallsided games in junior and senior rugby league players. J Strength Cond Res, 2012; 26: 487-491

Gastin PB, McLean O, Spittle M, Breed RV. Quantification of tackling demands in professional Australian football using integrated wearable athlete tracking technology. J Sci Med Sport, 2013; 6:589-93

Hill-Haas S, Rowsell G, Dawson B, Coutts A. Acute physiological responses and time-motion characteristics of two small-sided training regimens in youth soccer players. J Strength Cond Res, 2009; 23: 111-115

Hill-Haas S, Coutts A, Dawson B, Rowsell G. Time-motion characteristics and physiological responses of small-sided games in elite youth players: the influence of player number and rule changes. J Strength Cond Res, 2010; 24: 2149-2156

Hill-Haas S, Coutts A, Rowsell G, Dawson B. Generic versus small-sided game training in soccer. Int J Sports Med, 2009; 30: 636-642

Hill-Haas S, Dawson B, Coutts A, Rowsell G. Physiological responses and time-motion characteristics of various small-sided soccer games in youth players. J Sports Sci, 2009; 27: 1-8

Hill-Haas S, Dawson B, Impellizzeri FM, Coutts A. Physiology of small sided games training in football. A systematic review. Sports Med, 2011; 41: 199-200

Hopkins WG. Spreadsheets for analysis of controlled trials, with adjustment for a subject characteristic. Sport Science, 2006; 10: 46-50

Hopkins WG, Marshall SW, Batterham AM, Hanin J. Progressive statistics for studies in sports medicine and exercise science. Med Sci Sports Exerc, 2009; 41: 3-13

Impellizzeri F, Marcora SM, Castagna C, Reilly T, Sassi A, Iaia F, Rampinini E. Physiological and performance effects of generic versus specific aerobic training in soccer players. Int J of Sports Med, 2006; 27: 483-492

Jones S, Drust B. Physiological and technical demands of $4 \mathrm{v} 4$ and $8 \mathrm{v} 8$ in elite youth soccer players. Kinesiology, 2007; 39: 150-156

Katis A, Kellis E. Effects of small-sided games on physical conditioning and performance in young soccer players. J Sports Sci Med, 2009; 8: 374-380

Kennett DC, Kempton T, Coutts AJ. Factors affecting exercise intensity in rugby-specific small-sided games. J Strength Cond Res, 2012; 26: 2037-2042

Köklü Y. A comparison of physiological responses to various intermittent and continuous small-sided games in young soccer players. J Hum Kinet, 2012; 31: 89-96

Köklü Y, Aşçi A, Koçak FU, Alemdaroğlu U, Dündar U. Comparison of the physiological responses to different small-sided games in elite young soccer players. J Strength Cond Res, 2011; 25: 1522-1528

Rampinini E, Impellizzeri FM, Castagna C, Abt G, Chamari K, Sassi A, Marcora SM. Factors influencing physiological responses to small-sided soccer games. J Sports Sci, 2007; 25: 659-666

Rodrigues V, Mortimer L, Condessa L, Coelho D, Soares D, García E. Exercise intensity in training sessions and official games in soccer. J Sports Sci Med, 2007; 6: 57-58

Sampaio J, García G, Maçãs V, Ibáñez S, Abrantes C, Caixinha P. Heart rate and perceptual responses to $2 \times 2$ and 3 × 3 small-sided youth soccer games. J Sports Sci Med, 2007; 6: 121-122

Sampaio J, Lago C, Gonçalves B, Maçãs VM, Leite N. Effects of pacing, status and unbalance in time motion variables, heart rate and tactical behaviour when playing 5-a-side football small-sided games. J Sci Med Sport, 2013, doi: 10.1016/j.jsams.2013.04.005

Sampaio J, Maçãs V. Measuring tactical behaviour in football. Int J Sports Med, 2012; 33: 395-401.

Tessitore A, Meeusen R, Piacentini M, Demarie S, Capranica L. Physiological and technical aspects of "6-aside" soccer drills. J Sports Med Phys Fit, 2006; 46: 36-43 
Varley MC, Fairweather IH, Aughey RJ. Validity and reliability of GPS for measuring instantaneous velocity during acceleration, deceleration, and constant motion. J Sports Sci, 2012; 30: 121-127

\section{Corresponding author:}

Julen Castellano Paulis

Department of Physical Education and Sport,

Faculty of Physical Activity and Sport Sciences

University of the Basque Country (UPV/EHU),

Portal de Lasarte 71, 01007 Vitoria-Gasteiz (Spain)

Phone: +34 945013525

Fax: +34 945013501

E-mail: julen.castellano@ehu.es 